\title{
Interspecific Comparisons of the Size of Neural Song Control Regions and Song Complexity in Duetting Birds: Evolutionary Implications
}

\author{
Eliot A. Brenowitz and Arthur P. Arnold \\ Department of Psychology and Laboratory of Neuroendocrinology, Brain Research Institute, University of \\ California, Los Angeles, California 90024
}

\begin{abstract}
Previous studies have demonstrated a correlation between song repertoire size and volume of song control regions (SCRs) in the brains of songbirds. In the present study we demonstrate that 2 congeneric species of tropical duetting wrens, the rufous-andwhite wren (Thryothorus rufalbus) and the bay wren ( $T$. nigricapillus), share the same relationship between SCR volume and vocal complexity. In each species, females sing in elaborate duets with males. Males of these species have similar song repertoire sizes; there is no significant difference between heterospecific males in the volumes of SCRs. Female rufous-and-white wrens have less than half as large a song repertoire as female bay wrens, and all of their SCRs measured are significantly smaller than those of bay wren females. This interspecific equivalence of the relationship between SCR volume and repertoire size suggests that the neural system regulating vocal behavior in songbirds is evolutionarily conservative in the manner in which it encodes song complexity.
\end{abstract}

Comparative neuroethological studies of a wide variety of species have yielded much insight into the neural basis of behavior. Observation of the great diversity of behaviors shown even by closely related species leads directly to a consideration of the evolution of brain-behavior relationships. We can, for example, ask whether the generation of new species from a common phyletic lineage involves fundamental changes in the manner by which neural circuits control the production of behavior. Relatively few experimental studies have directly addressed this topic, however. In the present study we explore this broad evolutionary issue with specific reference to the neuroendocrine system regulating song behavior in oscine birds.

Song is a stereotyped behavior that must be learned by juvenile songbirds (Marler and Mundinger, 1971), and the development of new song continues into adulthood in some species (Nottebohm and Nottebohm, 1978). An interconnected network of discrete brain nuclei has been shown to regulate the learning and production of vocalizations (Arnold, 1982; Bottjer et al., 1984; Nottebohm, 1980a, 1984). Neurons in several of these song control regions (SCRs) accumulate steroid hormones (Arnold, 1980; Arnold et al., 1976), which are known to play an important role in the activation of vocal behavior (Arnold,

\footnotetext{
Received Nov. 4, 1985; revised Apr. 14, 1986; accepted Apr. 21, 1986.

We are grateful to the Smithsonian Tropical Research Institute for providing access to their facilities in Panama. Our thanks to Rachel Levin and Susan Farabaugh for providing unpublished information, to Dale Sengelaub, Walter Wilczynski, and Harold Zakon for comments on the manuscript, and to Sherri Glaessner and Kathy Nordeen for technical assistance. This research was supported by NIH Grant NS 19645 to A.P.A. and USPHS Grants NS 07134 and MH 1579503 to E.A.B.

Correspondence should be addressed to Eliot A. Brenowitz, Department of Psychology, 1283 Franz Hall, University of California, Los Angeles, CA 90024. Copyright (C) 1986 Society for Neuroscience $0270-6474 / 86 / 102875-05 \$ 02.00 / 0$
}

1975; Pröve, 1974). Though song is restricted to males in most species, in scveral tropical species the females also sing and participate in elaborate vocal duets with males (Brenowitz et al., 1985).

In many species, individuals have a song repertoire consisting of several versions of the species-specific song (Kroodsma, 1982). Each of these song types must be learned, either by imitation or improvisation (e.g., Marler et al., 1972). Furthermore, different individuals within a species may have different-sized song repertoires. Thus individuals may differ in the complexity of vocal behavior learned and produced. This individual variability in vocal ability provides a powerful tool in the search for neural correlates to the complexity of behavior that is learned. We can, for example, ask whether quantifiable anatomical features of the neural song control system vary consistently and in congruity with individual differences in behavioral song complexity. Nottebohm et al. (1981) used this approach to show that in male canaries (Serinus canarius) there is a significant positive correlation between the number of song syllables produced by a given bird and the volume of 2 neural SCRs - the caudal nucleus of the ventral hyperstriatum $(\mathrm{HVc})$ and the robust nucleus of the archistriatum (RA). Similar correlations between the volume of $\mathrm{HVc}$ and RA and song complexity have also been reported for female canaries induced to sing by testosterone (Nottebohm, 1980b), and between populations of marsh wrens having different song repertoire sizes (Canady et al., 1984).

The correlation between SCR size and repertoire size could result from 1 of 3 causal relationships: (1) SCR size could determine repertoire size; (2) repertoire size could determine SCR size; or (3) other factors could simultaneously influence both SCR size and song repertoire size. These potential underlying functional relationships give rise to the observed numerical correlations between these traits. We can ask, in addition, whether different species show the same numerical correlation, which would imply that they also have the same functional relationships among factors involved in the organization of song behavior. In other words, do related species follow the same "rules" for the neural control of vocalization? This question has broader relevance to the evolution of the neural song control system in birds. As avian phyletic lineages give rise to new species over time, does the functional relationship between relative SCR size and song complexity remain constant across the daughter species? If so, then this might imply that the "rules" by which neural networks produce complex behaviors are conserved in the speciation event(s). Or, alternatively, does speciation involve a reorganization of the way in which neural circuits encode behavior, so the relationship between song complexity and SCR volume changes when new species arise?

Such evolutionary questions can be addressed through comparative studies of different species. It is possible to exploit the 
tremendous diversity of vocal adaptations shown by different avian taxa and choose interesting species for comparison. In selecting species in which to compare the relationship between SCR volume and song repertoire size, there are several potentially confounding factors that need to be considered. The most obvious is the effect of body size. If 2 species differ in the same direction in both song repertoire and body size, it may be difficult to distinguish the relative effects of these 2 factors on SCR volumc. This problem of allometry can bc avoided by comparing species that are similar in body size or in which song repertoire and body size differ in opposing directions.

A second potential problem is that the relationship between 2 variables, such as song repertoire size and SCR volume, may vary in widely separated taxonomic groups (Clutton-Brock and Harvey, 1984; Ridley, 1983). Quantitative comparisons of species selected from such distant taxonomic groups may not be justified. It is important to choose the appropriate taxonomic level for interspecific comparisons. Potential difficulties can be minimized by comparing closely related species from monophyletic lineages, such as congeners.

With these caveats in mind, we compare, in the present study, the relationship between relative SCR volume and song repertoire size in 2 congeneric species of duetting wrens, the rufousand-white wren (Thryothorus rufalbus) and the bay wren ( $T$. nigricapillus), both of which are found in Central to South America. Males and females within each species cannot be readily distinguished by plumage pattern or body size. Females of each species sing and engage in elaborate vocal duets with males. In rufous-and-white wren duets, the male and female overlap in time of song delivery (Farabaugh, 1983), whereas bay wren males and females rapidly alternate their vocalizations in a precisely timed manner(R. Levin, unpublished observations). Males and females of both species possess repertoires of song types used in duets. Repertoire size is about the same for male rufousand-white wrens (mean $\pm \mathrm{SD}=14.0 \pm 3.3$ song types; Farabaugh, 1983) and male bay wrens (16.5 \pm 6.4 ; R. Levin, unpublished observations). However, repertoire size is much smaller for female rufous-and-white wrens $(6.0 \pm 1.4$; Farabaugh, 1983) than for female bay wrens (15.2 \pm 0.5 ; R. Levin, unpublished observations). Average body size is only slightly greater for rufous-and-white wrens (bill to tail $=14.6 \mathrm{~cm}$ ) than for bay wrens $(14.0 \mathrm{~cm})$ (Ridgely, 1981). We therefore have an excellent situation for comparing the relationship between SCR volume and song repertoire size in males and females of these 2 species, with each sex acting as a control for the other. Because these species have comparable overall body sizes, measures of SCR volume relative to body size are equivalent to measures of absolute SCR volume. If the underlying functional relationship between SCR volume and repertoire size was conserved as these species arose from a shared ancestral lineage, we would expect to observe no difference in song region volumes of males, which have quite similar repertoire sizes. Conversely, we predict larger SCR volumes in female bay wrens than in female rufousand-white wrens, given that bay wren females have much larger repertoires. If the evolution of these species involved alteration of the mechanism of neural encoding of complex song, there would be no theoretical basis for expecting to observe any consistent interspecific patterns in SCR volume as a function of repertoire size.

\section{Materials and Methods}

Rufous-and-white wrens and bay wrens were captured in mist nets in the provinces of Panama and Colon in the Republic of Panama in Central America. Birds were attracted into nets with playback of conspecific song duets. In nearly all cases, the captured birds were observed to duet in response to playbacks immediately before entering the net. All birds had fully developed gonads, indicating that they wcre in brecding condition.
Each bird was anesthetized with Equithesin and then perfused with saline, followed by a $10 \%$ formalin solution. The entire head was placed in $10 \%$ formalin for protection during transport to the United States. To allow greater penetration by the formalin solution, a small window was opened at the base of the skull. The brains were subsequently removed and placed in a 10\% buffered formalin solution for at least 1 week before being weighed and embedded in gelatin. Transverse frozen sections were cut serially at a thickness of $50 \mu \mathrm{m}$ and collected in avian saline. Alternate sections were mounted and stained with either thionin (bay wrens) or cresyl violct (rufous-and-whitc wrens).

The volumes of 4 SCRs (HVc, RA, area X of the parolfactory lobe and nXII, the hypoglossal motor nucleus) and of 2 thalamic nuclei unrelated to vocal control, the nucleus rotundus (Rt) and the pretectal nucleus $(\mathrm{Pt})$, were measured. A magnified image of stained sections was projected at $46 \times$ on paper, the perimeter of the relevant nucleus was traced, and the area calculated, using a digitizing tablet and microcomputer. Areas were multiplied by the sampling interval of $100 \mu \mathrm{m}$ to obtain volume. Total volume for each nucleus was the sum of all such individual volumes. Five males and 5 females of each species were analyzed.

Volumes of brain regions were compared for the same sex between species, as well as between sexes within and between each species. Data were tested with Wilcoxon's 2-sample rank-sum test (Snedecor and Cochran, 1967). Statistical significance was accepted at the 0.05 alpha level, 2-tailed.

\section{Results}

\section{Conspecific intersexual comparisons}

Table 1 presents male : female ratios for the mean volumes of the brain regions measured [the values shown for the bay wren differ slightly from those in Brenowitz et al. (1985) because of the increased sample size analyzed in the present study]. There is no significant difference between male and female bay wrens in the volume of any of the brain regions measured. $\mathrm{HVc}_{\mathrm{c}} \mathrm{RA}$, and area $\mathrm{X}$ are larger $(p<0.05)$ in male rufous-and-white wrens than in conspecific females. $\mathrm{Rt}, \mathrm{Pt}$, and $\mathrm{nXII}$, however, do not differ in size $(p>0.05)$ between the sexes of this species.

For each of the SCRs measured, male : female volume ratios are greater for rufous-and-white wrens than for bay wrens; thus the differences between males and females are more pronounced in rufous-and-white wrens. This is consistent with the observation of considerable differences in song repertoire size between male and female rufous-and-white wrens; bay wren males and females, in contrast, have similar repertoire sizes.

Male: female ratios for the volumes of brain regions not involved in song control $(\mathrm{Rt}, \mathrm{Pt})$ in rufous-and-white wrens are comparable to, or even lower than, those for the same regions in bay wrens.

\section{Interspecific comparisons}

Volumes of HVc, RA, area X, nXII, and of Rt and Pt in males of the 2 wren species are presented in Figure 1. There are no significant differences $(p>0.05)$ between male rufous-and-white wrens and male bay wrens in the volumes of any of these brain nuclei. Males of these species have song repertoires of about equal size.

Figure 2 presents the volumes of these same nuclei in the brains of females of these species. RA, HVc, area X, and nXII are an average of $78,55,43$, and $26 \%$ larger, respectively, in female bay wrens than in female rufous-and-white wrens. These differences are significant $(p<0.05)$. Pt is the same size in females of these species $\left(p^{\prime}>0.05\right)$, while $\mathrm{Rt}$ is $78 \%$ larger in female rufous-and-white wrens than in female bay wrens $(p<$ 0.05 ). Bay wren females have more than twice the average song repertoire size of rufous-and-white wren females.

As an additional means of analyzing the repertoire size-SCK volume correlations of the 2 species, we can compare the volumes of these brain nuclei in male rufous-and-white wrens and female bay wrens, which also have similar song repertoire sizes. 


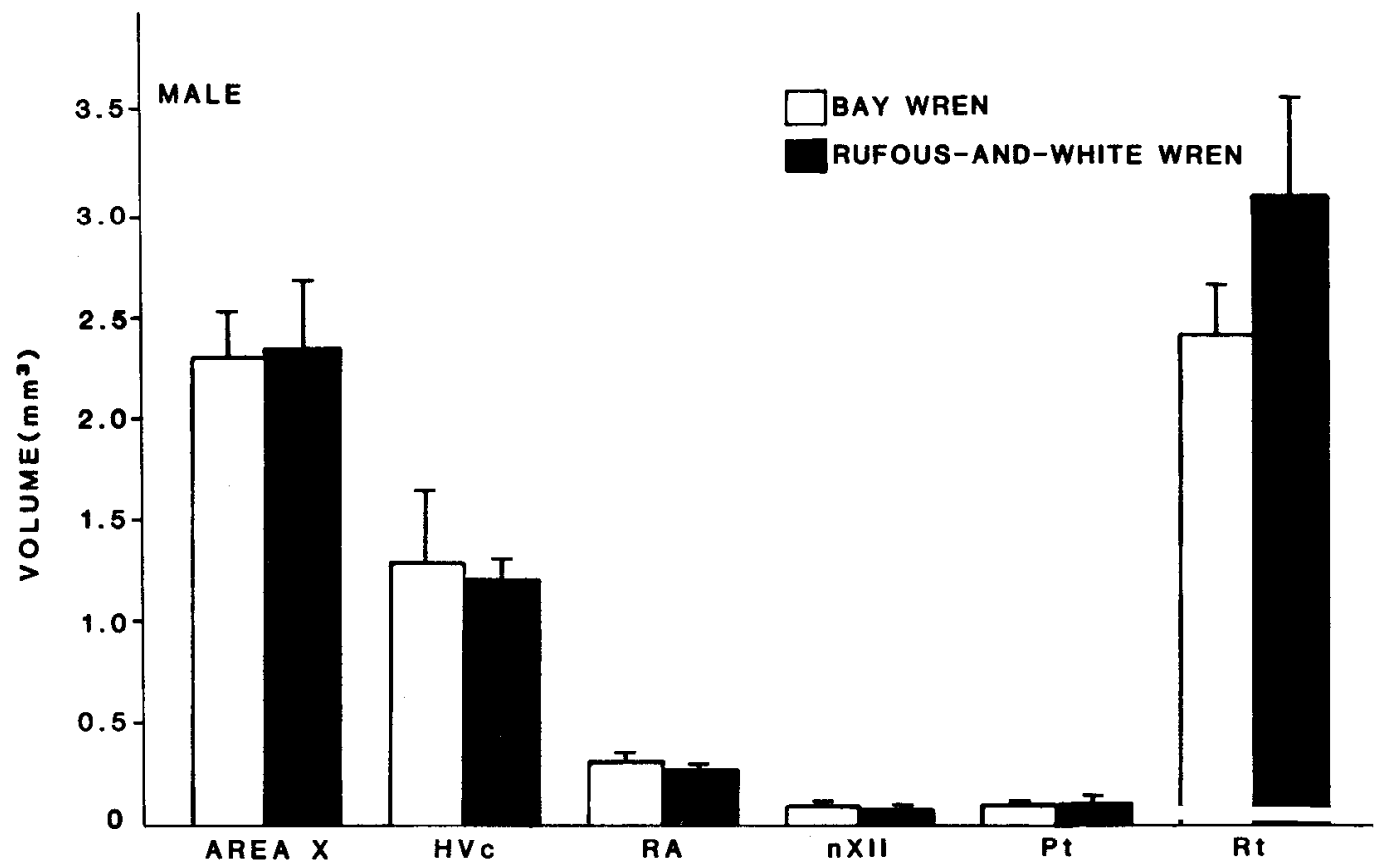

Figure 1. Volumes (right plus left, mean $\pm 1 \mathrm{SD}$ ) of 4 neural regions involved in song behavior (Hvc, $R A$, area $X$, and $n X I I)$ and of 2 regions not involved in song $(P t$ and $R t)$ in 5 male bay wrens and 5 male rufous-and-white wrens.

There is no significant difference between male rufous-and white wrens and female bay wrens in the volumes of any of the measured brain regions. In the converse comparison of brain region volumes, female rufous-and-white wrens have a song repertoire less than half as large as that of male bay wrens. HVc, RA, and area $X$ are significantly larger in male bay wrens than in female rufous-and-white wrens, Pt and nXII do not differ in size $(p>$ 0.05 ), and $\mathrm{Rt}$ is significantly larger in rufous-and-white wren females than in bay wren males.

\section{Discussion}

We predicted that, if these 2 species had the same neural mechanism for encoding behavioral song complexity, there would be no difference in the song region volumes of males, which have very similar repertoire sizes. Female bay wrens, however, would be expected to have larger SCRs than female rufous-and-white wrens, since the bay wren females have more than twice as large an average song repertoire size. These predictions are clearly supported by the results of our analysis. As is shown in Figure 1 , there is no significant difference between males in the size of any of the brain regions measured. Figure 2 , however, shows that all the song regions are significantly larger in female bay wrens than in female rufous-and-white wrens. Rt also differs in size between females of these species, but in the opposite direction from the song regions: it is larger in female rufous-andwhite wrens. This may be due to the slightly greater body size

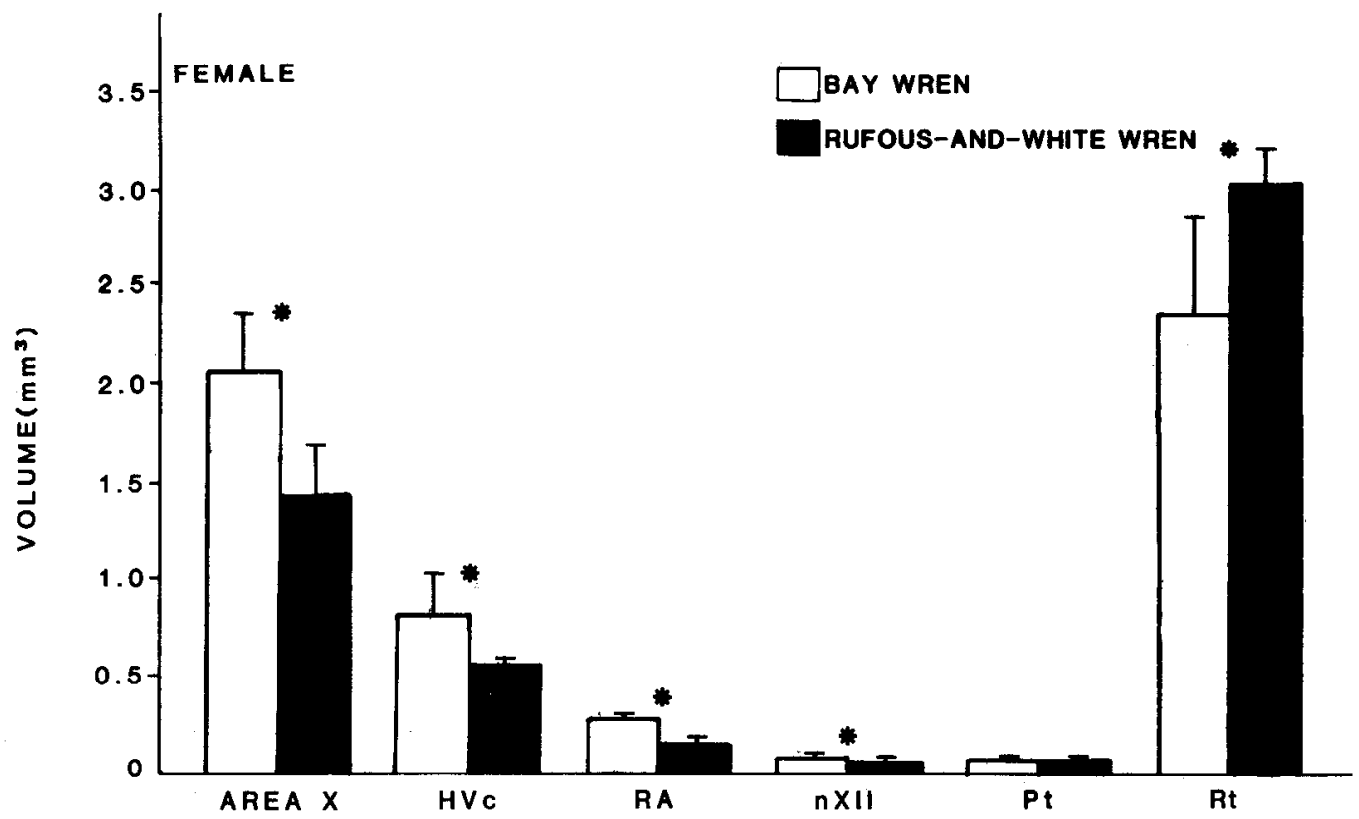

Figure 2. Volumes (right plus left, mean $\pm 1 \mathrm{SD}$ ) of 4 neural SCRs and 2 nonvocal regions in 5 female bay wrens and 5 female rufous-and-white wrens. *Volumes for the 2 species are significantly different at $p<0.05$ (Wilcoxon's 2 -sample rank-sum test). 


\begin{tabular}{lllllll}
\hline Table 1. Male : female ratios for volumes of brain regions & & & & \\
& & & & & \\
& HVc & RA & Area X & nXII & Rt & Pt \\
\hline Rufous-and-white wren & $2.16^{*}$ & $1.70^{*}$ & $1.68^{*}$ & 1.06 & 1.02 & 0.99 \\
Bay wren & 1.50 & 1.10 & 1.13 & 1.02 & 1.02 & 1.05 \\
\hline
\end{tabular}

* Male and female volumes are significantly different $(p<0.05$; Wilcoxon's 2-sample rank-sum test).

of female rufous-and-white wrens, or to some unknown interspecific difference in visually guided behavior. The observation that only the song regions are larger in female bay wrens strongly suggests that differences observed between females of these species in these regions of the brain are in fact related to differences in song complexity. These data refute the alternative possibility that interspecific differences in SCR size are due to differences in body size. The fact that males do not differ in SCR size further suggests that differences observed in females are not the artifactual result of possible differences in histological procedure. Rather, the interspecific male equivalency of SCR volume and song repertoire size, coupled with the female differences in both factors, lend rigorous support to the conclusion that the same functional relationship between vocal complexity and SCR volume was conserved during the evolutionary event(s) that gave rise to these 2 species from a common lineage.

It is significant that male rufous-and-white wrens and female bay wrens also match in song repertoire size and SCR volume, whereas female rufous-and-white wrens and male bay wrens differ on both of these factors. This further supports the conclusion that these species have the same functional relationship between SCR volume and vocal complexity. In addition, it suggests that males and females also have the same functional relationship between these parameters. Table 1 demonstrates this as well. Male and female bay wrens have similar song repertoire sizes and show no differences in the volume of any SCR. Male rufous-and-white wrens, however, have much larger repertoires than do conspecific females and accordingly have larger SCRs. It appears, then, that the neural song systems of females encode vocal complexity according to the same structural "rules" as do those of males. This is consistent with the observation that, rather than having evolved novel song control systems in the brain, females of duetting species have developed neural song systems extremely similar to those of males, both in structure (Brenowitz et al., 1985) and hormone sensitivity (Brenowitz and Arnold, 1985).

Behavioral factors other than repertoire size may also influence SCR volume. For example, one can hypothesize a priori that interspecific differences in duetting pattern (i.e., overlapping duets in rufous-and-white wrens, alternating duets in bay wrens) might be reflected in SCR size. If this were true, then we would predict that SCR volume would differ in males of these species, despite their match in repertoire size. The fact that SCR size does not differ between heterospecific males, however, argues against this hypothesis.

Our findings are consistent with those of previous studies (Canady et al., 1984; Nottebohm, 1980b; Nottebohm et al., 1981 ) in demonstrating a correlation between SCR volume and repertoire size. However, the previous studies analyzed only HVc and RA. The present report indicates that this correlation is also seen in area $\mathrm{X}$ and even, though to a lesser degree, in nXII.

The present study also extends beyond these earlier reports, in that we compared the functional relationship between SCR volume and behavioral song complexity across species. Because these congeners are very closely matched in body size, measures of SCR volume relative to body size translate directly to measurcs of absolutc SCR volumc. Heterospecific males match in SCR volume and repertoire size, while females differ in both traits. This suggests that the relationship between SCR volume and repertoire size can be viewed as being evolutionarily conservative. For these 2 congeners, at least, generation of new species from a shared ancestral lineage did not modify the structural "rules" by which vocal complexity is encoded by those neural regions that regulate the learning and production of songs.

It is possible that interspecific similarities in the relationship between song complexity and SCR volume may arise independently by convergent evolution. In the present case of closely related species, however, it seems more justified to invoke common phylogenetic inheritance (homology) to account for these similarities. It should be extremely interesting to compare, in future studies, this relationship between less closely related species, and to determine at what taxonomic levels discontinuities might occur. In addition, there is the remaining challenge of elucidating the direction of the causal correlation between SCR volume and the complexity of vocal behavior that can be learned and produced by birds.

\section{References}

Arnold, A. P. (1975) The effects of castration and androgen replacement on song, courtship, and aggression in Zebra Finches (Poephila guttata). J. Exp. Zool. 191: 309-326.

Arnold, A. P. (1980) Quantitative analysis of sex differences in hormone accumulation in the Zebra Finch brain: Methodological and theoretical issues. J. Comp. Neurol. 189: 75-94.

Arnold, A. P. (1982) Neural control of passerine song. In Acoustic Communication in Birds, Vol. 1, D. E. Kroodsma and E. H. Miller, eds., pp. 75-94, Academic, New York.

Arnold, A. P., F. Nottebohm, and D. W. Pfaff (1976) Hormone accumulating cells in vocal control and other brain regions of the Zebra Finch (Poephila guttata). J. Comp. Neurol. 155: 487-512.

Bottjer, S. W., E. A. Miesner, and A. P. Arnold (1984) Forebrain lesions disrupt development but not maintenance of song in passerine birds. Science 224: 901-903.

Brenowitz, E. A., and A. P. Arnold (1985) Lack of sexual dimorphism in steroid accumulation in vocal control brain regions of duetting song birds. Brain Res. 344: 172-175.

Brenowitz, E. A., A. P. Arnold, and R. N. Levin (1985) Neural correlates of female song in tropical duetting birds. Brain Res. 343:104112.

Canady, R. A., D. F. Kroodsma, and F. Nottebohm (1984) Population differences in complexity of a learned skill are correlated with the brain space involved. Proc. Natl. Acad. Sci. USA 81: 6232-6234.

Clutton-Brock, T. H., and P. H. Harvey (1984) Comparative approaches to investigating adaptation. In Behavioral Ecology: An Evolutionary Approach, J. R. Krebs and N. B. Davies, eds., pp. 7-29, Blackwell, Oxford.

Farabaugh, S. M. (1983) A comparative study of duet song in tropical Thryothorus wrens. Ph.D. dissertation, University of Maryland, College Park, MD.

Kroodsma, D. E. (1982) Song repertoires: Problems in their definition and use. In Acoustic Communication in Birds, Vol. 2, D. E. Kroodsma and E. H. Miller, eds., pp. 125-146, Academic, New York.

Marler, P. (1981) Birdsong: The acquisition of a learned motor skill. Trends Neurosci. 4: 88-94.

Marler, P., and P. Mundinger (1971) Vocal learning in birds. In Ontogeny of Vertebrate Behavior, H. Moltz, ed., pp. 389-450, Academic, New York.

Marler, P., P. Mundinger, M. S. Waser, and A. Lutjen (1972) Effects of acoustical stimulation and deprivation of song development in the Red-winged Blackbird (Agelaius phoeniceus). Anim. Behav. 20: 586606. 
Nottebohm, F. (1980a) Brain pathways for vocal learning in birds: A review of the first 10 years. Prog. Psychobiol. Psychol. 9: 85-125.

Nottebohm, F. (1980b) Brain correlates of a learned motor skill. Verh. Dtsch. Zool. Ges. 1980: 262-267.

Nottebohm, F. (1984) Vocal learning and its possible relation to replaceable synapses and neurons. In Biological Perspectives on Language, D. Caplan, A. R. Lecouts, and A. Smith, eds., pp. 65-95, MIT Press, Cambridge, MA.

Nottebohm, F., and M. Nottebohm (1978) Relationship between song repertoire and age in the canary Serinus canarius. Z. Tierpsychol. 46: 298-305.

Nottebohm, F., S. Kasparian, and C. Pandazis (1981) Brain space for a learned task. Brain Res. 213: 99-109.
Pröve, E. (1974) Der Einfluss von Kastration und Testosteronsubstitution auf das Sexualverhalten männlicher Zebrafinken (Taenopygia guttata castanotis Gould). J. Ornithol. 115: 338-347.

Ridgely, R. S. (1981) A Guide to the Birds of Panama, Princeton U. P., Princeton, NJ.

Ridley, M. (1983) The Explanation of Organic Diversity: The Comparative Methods and Adaptations for Mating. Cambridge U. P., Cambridge, UK.

Snedecor, G. W., and W. G. Cochran (1967) Statistical Methods, 6th Ed., Iowa State U. P., Ames, IA. 